\title{
The clinical effective dose of rocuronium for lightwand tracheal intubation after induction with alfentanil, propofol, and low concentrations of sevoflurane
}

\author{
Hee-Yeon Park, Dongchul Lee, Kyung-Cheon Lee, and Seung-Hwan Kim \\ Department of Anesthesiology and Pain Medicine, Gil Medical Center, Gachon University of Medicine and Science, Incheon, Korea
}

Background: The aim of this study was to determine the clinical effective dose of rocuronium for tracheal intubation using a lightwand after induction with propofol, alfentanil, and a low concentration of sevoflurane.

Methods: Twenty-eight adults scheduled to undergo elective surgery lasting less than one hour were enrolled in this study. All patients received alfentanil (10 $\mu \mathrm{g} / \mathrm{kg})$ and propofol (1.5 mg/kg) for the induction of anesthesia. Tracheal intubation using a lightwand was attempted 3 minutes after administering rocuronium and mask ventilation with 2 vol\% of sevoflurane. The initial rocuronium dose was $0.5 \mathrm{mg} / \mathrm{kg}$. The rocuronium dose for consecutive patients, determined by Dixon's up-and-down method, was increased or decreased by $0.05 \mathrm{mg} / \mathrm{kg}$ according to the result of the previous patient. The mean arterial pressure and heart rate were recorded before induction, 1 min before intubation, 1 and 2 min after intubation.

Results: The $50 \%$ clinical effective dose $\left(\mathrm{cED}_{50}\right)$ of rocuronium for tracheal intubation using a lightwand was $0.20 \pm 0.05$ $\mathrm{mg} / \mathrm{kg}$ according to Dixon's up and down method. Isotonic regression revealed the $\mathrm{cED}_{50}$ and $\mathrm{cED}_{95}(95 \% \mathrm{confidence}$ intervals) to be $0.20 \mathrm{mg} / \mathrm{kg}(0.10-0.3 \mathrm{mg} / \mathrm{kg})$ and $0.35 \mathrm{mg} / \mathrm{kg}(0.16-0.49 \mathrm{mg} / \mathrm{kg})$, respectively.

Conclusions: The $\mathrm{cED}_{50}$ and $\mathrm{cED}_{95}$ of rocuronium for tracheal intubation using the lightwand were $0.20 \mathrm{mg} / \mathrm{kg}$ and $0.35 \mathrm{mg} / \mathrm{kg}$, respectively, after induction with alfentanil, propofol, and a low concentration of sevoflurane. (Korean J Anesthesiol 2010; 59: 82-86)

Key Words: Dixon's up-and-down method, Lightwand, Rocuronium.

Received: January 8, 2010. Revised: 1st, January 11, 2010; 2nd, March 14, 2010. Accepted: May 17, 2010.

Corresponding author: Dongchul Lee, M.D., Department of Anesthesiology and Pain Medicine, Gachon University of Medicine and Science Gil Medical Center, 1198, Guwol-dong, Namdong-gu, Incheon 405-760, Korea. Tel: 82-32-460-3637, Fax: 82-32-469-6319, E-mail: suasdad@nate.com (c) This is an open-access article distributed under the terms of the Creative Commons Attribution Non-Commercial License (http:// creativecommons.org/licenses/by-nc/3.0/), which permits unrestricted non-commercial use, distribution, and reproduction in any medium, provided the original work is properly cited. 


\section{Introduction}

Intravenous or volatile anesthetics and muscle relaxants provide adequate intubation conditions in the induction of general anesthesia that requires endotracheal intubation. Two or three times the $95 \%$ clinical effective dose $\left(\mathrm{cED}_{95}\right.$; dose for $95 \%$ depression of twitch height) of muscle relaxants, which is the usual intubation dose, can achieve adequate intubation conditions quickly, but prolongs recovery time of neuromuscular function, making it unsuitable for short surgery. Rocuronium is a non-depolarizing muscle relaxant with the most rapid onset of action and allows intubation within $2 \mathrm{~min}$ at a lower dose than the usual intubation dose $[1,2]$. Rocuronium is therefore preferred for short procedures or surgery that does not require profound neuromuscular blockade.

Lightwand tracheal intubation is a useful technique for patients with limited mouth opening or restricted cervical spine movement, as well as for those with unexpected failed intubation $[3,4]$. This technique is relatively simple, with only a $1 \%$ failure rate and a $92 \%$ success rate after the first attempt [5]. According to Massó et al. [6], the success rate of tracheal intubation using a lightwand was increased by rocuronium $0.6 \mathrm{mg} / \mathrm{kg}$ compared to that without the muscle relaxants. However, there is no data on the low rocuronium dose that can offer acceptable intubation conditions with lightwand. The intubation dose of rocuronium, which has been defined for laryngoscopy-guided tracheal intubation, cannot be directly translated to the dose for lightwand technique. Therefore, we aimed to determine the clinical effective dose of rocuronium for lightwand tracheal intubation.

\section{Materials and Methods}

The study was approved by the institutional review board and written informed consent was obtained from the subjects. American Society of Anesthesiologists physical status I-II adult patients who required general anesthesia with orotracheal intubation for elective surgery lasting less than one hour were examined. Patients with a history of previous difficult intubation or in whom a difficult intubation was suspected were excluded. Patients with a known abnormal airway, limited cervical spine movement, and body mass index (BMI) $>30 \mathrm{~kg} /$ $\mathrm{m}^{2}$ were also excluded.

Upon arrival at the operating room, the following measurements were assessed for each patient: modified Mallampati classification (in the sitting position, tongue maximally forward on phonation), mouth opening (MO; the distance between the upper and lower incisors with the mouth fully open), and the thyromental distance (TMD; the distance from thyroid notch to the lower border of the mandibular mentum with the neck fully extended). Patients with modified Mallampati classification III or IV, MO $<35 \mathrm{~mm}$ and TMD $<65 \mathrm{~mm}$ were excluded.

Midazolam $30 \mu \mathrm{g} / \mathrm{kg}$ was administered intravenously 5 min before the induction of anesthesia. Standard monitors, including an electrocardiogram, noninvasive blood pressure, and pulse oximetry were applied. Neuromuscular function was assessed by train-of-four (TOF) stimulation of the ulnar nerve, using TOF-Watch ${ }^{\circledR}$ (Organon Teknika, The Netherlands) during anesthesia induction. Anesthesia was induced with alfentanil ( $10 \mu \mathrm{g} / \mathrm{kg}$ ), followed by propofol (1.5 mg/kg) intravenously. After confirming mask ventilation, the patients received intravenous rocuronium. The rocuronium dose was $0.5 \mathrm{mg} / \mathrm{kg}$ for the first patient. If lightwand intubation was successful, the rocuronium dose was decreased by $0.05 \mathrm{mg} / \mathrm{kg}$ in the consecutive patient. On the other hand, if it failed, the dose was increased by $0.05 \mathrm{mg} / \mathrm{kg}$ in the consecutive patient. After rocuronium was injected, all patients were mask-ventilated mechanically with a tidal volume of $10 \mathrm{ml} / \mathrm{kg}$ at a respiratory rate of 14 breaths/ min and ventilation was maintained with $2 \%$ sevoflurane and inspired gas in $100 \%$ oxygen $6 \mathrm{~L} / \mathrm{min}$ for 3 minutes. Tracheal intubation using a lightwand (Surch-Lite ${ }^{\mathrm{TM}}$, Aaron Medical Industry, USA) was attempted by one anesthesiologist with more than eight years experience in this technique. We used 7.5-mm-ID and 7.0-mm-ID endotracheal tubes for male and female patients, respectively. The distal end of the lightwand and covering lubricated tube was bent at a $90^{\circ}$ angle ("hockey stick"), and the patient's head and neck were placed in the neutral position. The jaw was lifted forward by an assistant and the lightwand and tube were inserted. The ambient light was dimmed to allow the visualization of transillumination. The cuff of the tracheal tube was inflated immediately after withdrawal of the lightwand. The time from inserting the lightwand into the oral cavity to visible transillumination at the anterior portion of the patient's neck (defined as the search time) and to the confirmation of tracheal intubation with the visualization of three expiratory carbon dioxide waveforms during manual ventilation (defined as attempt duration) were measured.

When the search time exceeded 30 seconds or the endotracheal tube had been inserted into the esophagus, a second attempt was performed after mask ventilation with $2 \%$ sevoflurane and inspired gas in $100 \%$ oxygen for $1 \mathrm{~min}$. Intubation conditions were assessed using a scoring system (0: inability to insert tracheal tube into the trachea after two attempts, 1 : the presence of gross movement of limbs and/or severe cough lasting greater than 5 seconds after inserting the tracheal tube into the trachea using lightwand, 2: slight movement of limbs and/or some diaphragm movement after lightwand tracheal intubation, 3 : no movement of limbs and diaphragm after lightwand tracheal intubation). For score 0, a direct laryngoscopy was performed and the laryngoscopic Cormack grade and position of the 
vocal cord were recorded. A supplemental dose of rocuronium $(0.2 \mathrm{mg} / \mathrm{kg})$ and propofol $(0.5 \mathrm{mg} / \mathrm{kg})$ were then injected and tracheal intubation under direct laryngoscopy was attempted after mask ventilation for $2 \mathrm{~min}$. Successful lightwand intubation was defined as a 2 or 3 score, and failed lightwand intubation was defined as a 0 or 1 score. Patients were divided into two groups, Group S and group F, according to the results of lightwand tracheal intubation. The events including a peripheral oxygen saturation $<92 \%$, dental trauma, or mucosal trauma to the oral cavity or airway were noted.

We recorded the train-of-four (TOF) number/ratio that did not further decrease more than 3 times consecutively $3 \mathrm{~min}$ after administering the rocuronium. At this time, end tidal sevoflurane concentrations were also noted. The mean arterial pressure (MAP) and heart rates (HR) were measured before induction, $1 \mathrm{~min}$ before intubation, and 1 and $2 \mathrm{~min}$ after intubation.

Data is reported as the mean $\pm \mathrm{SD}$. Statistical analysis was performed using the SPSS version 13.0 for windows (SPSS Inc, Chicago, IL, USA). According to Dixon's up-and-down method [7], the study was continued until seven pairs of successfulfailed lightwand intubations had occurred. The 50\% clinical effective dose $\left(\mathrm{CED}_{50}\right)$ of rocuronium for lightwand tracheal intubation was defined as the mean of the median crossover doses. The data was also subjected to isotonic regression estimators for calculating the $\mathrm{cED}_{95}$ and the $95 \%$ confidence interval (CI). An adjusted response probability was easily calculated by the pooled adjacent-violators algorithm (PAVA) and the CI was estimated by bootstrapping approach [8]. The hemodynamic changes during induction in the successful intubation group were analyzed by repeated measures ANOVA. A $P$ value $<0.05$ was considered significant.

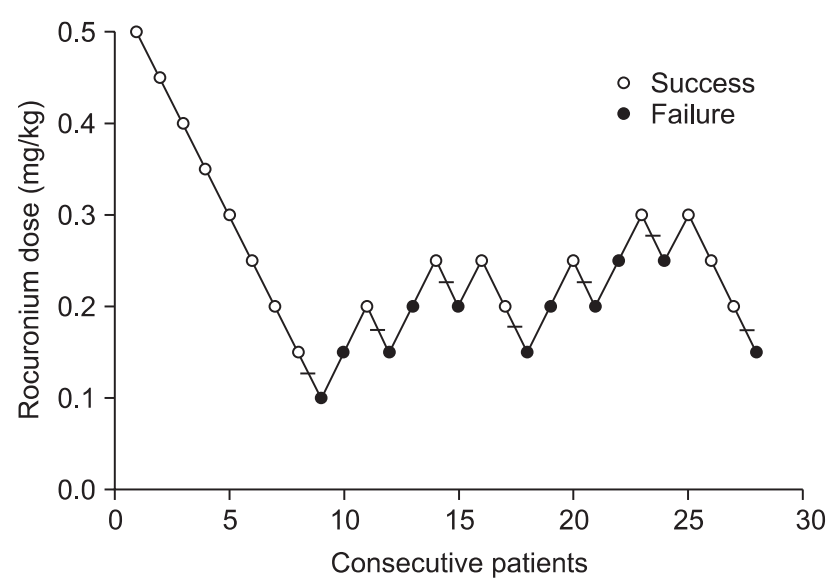

Fig. 1. Success or failure of intubation using the lightwand on the determined rocuronium dose. The mean \pm SD of the median rocuronium dose of seven success-failure pairs is $0.20 \pm 0.05 \mathrm{mg} / \mathrm{kg}$.

\section{Results}

Twenty-eight patients were enrolled in this study when seven pairs of successful-failed lightwand intubation had occurred (Fig. 1). There were no significant differences in gender, age, height, weight, BMI, Mallampati classification, TMD, or MO between the successful (Group S) and failed groups (Group F) for the lightwand tracheal intubation (Table 1). No Hypoxemia, dental trauma, or mucosal trauma during induction occurred in either group. The end-tidal sevoflurane concentration (means \pm SD) was $1.04 \pm 0.14$ vol\% after mask-ventilation for $3 \mathrm{~min}$, and there was no significant difference between the two groups. The TOF number ranged from one to two 3 min after injecting $0.45-$ $0.50 \mathrm{mg} / \mathrm{kg}$ rocuronium. The mean (range) of TOF ratio was $39 \%(14-78 \%$ ) for $0.25-0.4 \mathrm{mg} / \mathrm{kg}$ rocuronium and $55 \%$ (31$73 \%$ ) for $0.1-0.2 \mathrm{mg} / \mathrm{kg}$ rocuronium, respectively. The search time and attempt duration in Group S were $10.9 \pm 4.6$ seconds and $25.8 \pm 4.9$ seconds, respectively. For intubation condition score $0(n=5)$, endotracheal intubations under a direct laryngoscopy were successful and the Cormack grade was I or II in all patients (Table 1). However, the vocal cords were closed in two patients and mobile in one. Lightwand tracheal intubation was successful in the first attempt in all patients except for one in Group S. The MAP decreased significantly in group S 1 min before intubation compared to that before induction, and the HR increased significantly $1 \mathrm{~min}$ after intubation compared to

Table 1. Patients' Characteristics and Intubation Condition Score

\begin{tabular}{lcc}
\hline & Group S $(\mathrm{n}=17)$ & Group F $(\mathrm{n}=11)$ \\
\hline Age & $33.5 \pm 14.0$ & $36.4 \pm 15.1$ \\
Gender $(\mathrm{M} / \mathrm{F})$ & $8 / 9$ & $5 / 6$ \\
Height $(\mathrm{cm})$ & $168.0 \pm 10.3$ & $165.8 \pm 10.8$ \\
Weight $(\mathrm{kg})$ & $62.8 \pm 9.5$ & $61.2 \pm 10.9$ \\
BMI $\left(\mathrm{kg} / \mathrm{m}^{2}\right)$ & $22.4 \pm 2.0$ & $22.3 \pm 3.3$ \\
Mallampati class (I/II) & $7 / 10$ & $3 / 8$ \\
TMD $(\mathrm{cm})$ & $8.0 \pm 0.7$ & $7.6 \pm 0.8$ \\
MO $(\mathrm{cm})$ & $4.5 \pm 0.5$ & $4.4 \pm 0.3$ \\
Intubation condition score & & \\
0 & 0 & 5 \\
1 & 0 & 6 \\
2 & 8 & 0 \\
3 & 9 & 0 \\
\hline
\end{tabular}

Values are presented as mean \pm SD except for gender, Mallampati class, and intubation condition score. There were no significant differences between Group S (successful group for lightwand tracheal intubation) and Group F (failed group for lightwand tracheal intubation). Intubation condition score, 0 : inability to insert tracheal tube into the trachea after two attempts, 1 : the presence of gross movement of limbs and/or severe cough lasting greater than 5 seconds after inserting the tracheal tube into the trachea, 2: slight movement of limbs and/or some diaphragm movement after lightwand tracheal intubation, 3: no movement of limbs and diaphragm after lightwand tracheal intubation. BMI: body mass index, TMD: thyromental distance, MO: mouth opening. 
Table 2. Hemodynamic Changes during Anesthesia Induction in the Successful Intubation Using the Lightwand

\begin{tabular}{lccc}
\hline & Before induction & 1 min before intubation & 1 min after intubation \\
\hline MAP (mmHg) & $92.5 \pm 12.9$ & $68.7 \pm 9.3^{*}$ & $92.6 \pm 14.4$ \\
HR (beats/min) & $71.4 \pm 12.0$ & $64.6 \pm 14.2$ & $82.2 \pm 16.5^{*}$ \\
\hline
\end{tabular}

Values are presented as the mean \pm SD. MAP: mean arterial pressure, HR: heart rate. *P $<0.05$ compared to before induction.

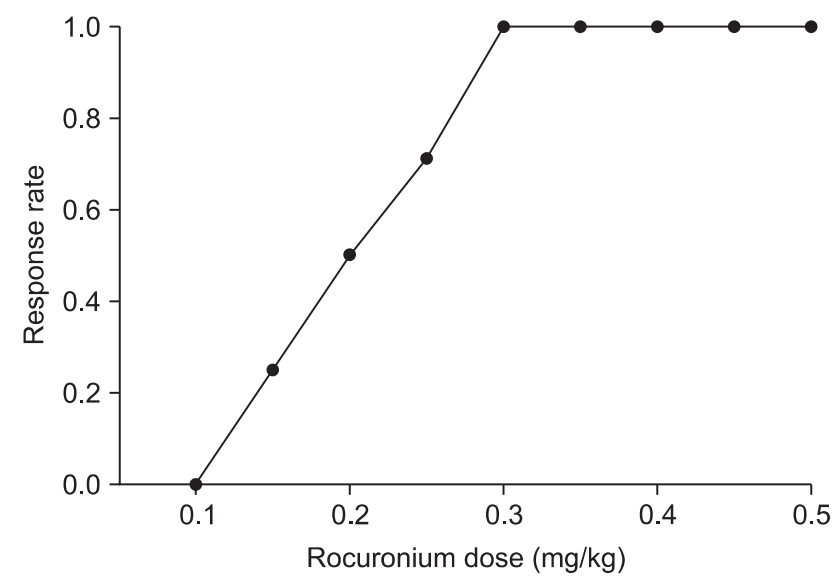

Fig. 2. Pooled-adjacent-violators algorithm (PAVA) response rate. The $50 \%$ and $95 \%$ clinical effective dose (95\% confidence interval) estimated from the PAVA response rate of rocuronium for intubation using the lightwand, were $0.20 \mathrm{mg} / \mathrm{kg}(0.09-0.30 \mathrm{mg} / \mathrm{kg})$ and 0.35 $\mathrm{mg} / \mathrm{kg}(0.16-0.49 \mathrm{mg} / \mathrm{kg})$, respectively.

that before induction (Table 2).

The dose of rocuronium for successful tracheal intubation using the lightwand in $50 \%$ of patients $\left(\mathrm{cED}_{50}\right)$ was $0.20 \pm 0.05$ $\mathrm{mg} / \mathrm{kg}$ according to Dixon's up and down method (Fig. 1). Isotonic regression, which was estimated from the PAVA rate, revealed an $\mathrm{CED}_{50}$ and $\mathrm{CED}_{95}(95 \% \mathrm{CI})$ of rocuronium $0.20 \mathrm{mg} /$ $\mathrm{kg}(0.09-0.30 \mathrm{mg} / \mathrm{kg})$ and $0.35 \mathrm{mg} / \mathrm{kg}(0.16-0.49 \mathrm{mg} / \mathrm{kg})$, respectively (Fig. 2).

\section{Discussion}

The $\mathrm{CED}_{50}$ and $\mathrm{cED}_{95}$ of rocuronium for tracheal intubation using lightwand were $0.20 \mathrm{mg} / \mathrm{kg}$ and $0.35 \mathrm{mg} / \mathrm{kg}$, respectively, after induction with propofol and alfentanil, and a low concentration of sevoflurane in patients with a normal airway anatomy.

Patients in whom a difficult intubation was suspected were excluded. In addition, patients with factors that could interfere with the ease and success of intubation using lightwand, including Mallampati class III and a BMI $\geq 30 \mathrm{~kg} / \mathrm{m}^{2}$ were also excluded [9]. The Cormack grade under a direct laryngoscopy in the five patients from Group F who could not be intubated using a lightwand was I or II, meaning that these patients did not have abnormal airway anatomy leading to difficult tracheal intubation. Another 6 patients in Group F showed severe cough and/or vigorous movement of the limbs after lightwand tracheal intubation. From the fact that lightwand intubation failed or was successful in the same dose, it was inferred that individual sensitivity to muscle relaxant would be reflected.

This study calculated the clinically effective dose of rocuronium required for lightwand tracheal intubation using Dixon's up and down method and isotonic regression. The rocuronium dose that provided clinically acceptable intubation conditions in $95 \%$ of patients when performing intubation using a lightwand was $0.35 \mathrm{mg} / \mathrm{kg}$, which is comparable to a low dose for intubation under direct laryngoscopy. Rocuronium $(0.1 \mathrm{mg} / \mathrm{kg})$ after induction with propofol $(2.5 \mathrm{mg} / \mathrm{kg})$ and alfentanil $(10 \mu \mathrm{g} /$ $\mathrm{kg}$ ) improved intubation conditions significantly compared to those without muscle relaxants, and rocuronium $(0.3 \mathrm{mg} / \mathrm{kg})$ provided acceptable intubation conditions in $90 \%$ of patients [10]. After induction with remifentanil $2 \mu \mathrm{g} / \mathrm{kg}$ and propofol $2 \mathrm{mg} / \mathrm{kg}$, rocuronium $0.3 \mathrm{mg} / \mathrm{kg}$ provided excellent and good intubation conditions in $90 \%$ and $9 \%$ of patients, respectively [11]. Schlaich et al. [12] reported that the intubation conditions were poor in $40 \%$ of patients without muscle relaxants after induction with propofol $(2-2.5 \mathrm{mg} / \mathrm{kg})$ and remifentanil $(0.5$ $\mu \mathrm{g} / \mathrm{kg} / \mathrm{min}$ ) for $3 \mathrm{~min}$. However, the addition of rocuronium $(0.45 \mathrm{mg} / \mathrm{kg}$ or $0.3 \mathrm{mg} / \mathrm{kg})$ to this regimen improved the intubation conditions significantly. In addition, reducing the intubation dose of rocuronium shortened its time course of action considerably.

Several factors contribute to tracheal intubation conditions. Satisfactory tracheal intubation can be achieved under deep anesthesia alone. However, increasing the dose of hypnotics and opioids may have adverse effects, such as hypotension or bradycardia, and there is still no guarantee that the optimal intubation conditions will be achieved in all patients without a muscle relaxant [1]. In addition, tracheal intubation without a muscle relaxant may increase the risk of airway trauma [13]. The administration of larger multiples of a relaxant's $\mathrm{ED}_{95}$ provides increased reliability and accelerates the onset for tracheal intubation but may prolong its duration of action, which is unsuitable for short surgery or outpatient surgery. However, rocuronium with a rapid onset profile can provide clinically acceptable intubation conditions at less than twice the $\mathrm{ED}_{95}$, the usual intubation dose [1]. Here, a clinically effective dose of rocuronium for lightwand tracheal intubation was obtained with usual doses of hypnotics and opioids that provided stable 
hemodynamic changes (Table 2).

The onset time of the neuromuscular blocking agent is associated with the dose administered [14]. In Koreans, the onset time is $191 \mathrm{~s}$ and $159 \mathrm{~s}$ with rocuronium $0.1 \mathrm{mg} / \mathrm{kg}$ and 0.3 $\mathrm{mg} / \mathrm{kg}$, respectively [15]. The interval between drug administration and laryngoscopy will be prolonged if tracheal intubation is performed with a small dose of nondepolarizing neuromuscular agent. Therefore, lightwand tracheal intubation was attempted when the TOF ratio had not further decreased more than 3 times consecutively 3 min after the administration of rocuronium.

This study has some limitations. First, objective data showing anesthetic depth are lacking. Although all patients received the same dose of hypnotics and opioids, they may have different degrees of anesthetic depth. Second, neuromuscular monitoring was not performed during the operation except during the induction period. Consequently, there is no information on the actual neuromuscular recovery time at these low doses. After injecting rocuronium $(0.25 \mathrm{mg} / \mathrm{kg})$, the time to spontaneous $90 \%$ recovery of the $\mathrm{T} 1$ twitch height at the adductor pollicis muscle was approximately $10 \mathrm{~min}$ [16]. These results indicate that the clinical effective dose of rocuronium for lightwand tracheal intubation calculated in the present study is suitable for short surgery or outpatient surgery.

In conclusion, the $\mathrm{cED}_{50}$ and $\mathrm{cED}_{95}$ of rocuronium for lightwand tracheal intubation under 2 vol\% inspired sevoflurane after induction with propofol $(2 \mathrm{mg} / \mathrm{kg})$ and alfentanil $(10 \mu \mathrm{g} /$ $\mathrm{kg}$ ) were $0.20 \mathrm{mg} / \mathrm{kg}$ and $0.35 \mathrm{mg} / \mathrm{kg}$, respectively. These are the clinically optimal doses of rocuronium when the lightwand technique is needed for short surgical procedures or outpatient surgery.

\section{References}

1. Kopman AF, Klewicka MM, Neuman GG. Reexamined: the recommended endotracheal intubating dose for nondepolarizing neuromuscular blockers of rapid onset. Anesth Analg 2001; 93: 954-9.

2. Miguel RV, Soto R, Dyches P. A double-blind, randomized comparison of low-dose rocuronium and atracurium in a desflurane anesthetic. J Clin Anesth 2001; 13: 325-9.
3. Hung OR, Pytka S, Morris I, Murphy M, Stewart RD. Lightwand intubation: II--Clinical trial of a new lightwand for tracheal intubation in patients with difficult airways. Can J Anaesth 1995; 42: 826-30.

4. Weis FR, Hatton MN. Intubation by use of the lightwand: experience in 253 patients. J Oral Maxillofac Surg 1989; 47: 577-80.

5. Hung OR, Pytka S, Morris I, Murphy M, Launcelott G, Stevens S, et al. Clinical trial of a new lightwand device (Trachlight) to intubate the trachea. Anesthesiology 1995; 83: 509-14.

6. Massó E, Sabate S, Hinojosa M, Vila P, Canet J, Langeron O. Lightwand tracheal intubation with and without muscle relaxation. Anesthesiology 2006; 104: 249-54.

7. Dixon WJ. Staircase bioassay: the up-and-down method. Neurosic Biobehav Rev 1991; 15: 47-50.

8. Pace NL, Stylianou MP. Advances in and limitation of up-anddown methodology: a précis of clinical use, study design, and dose estimation in anesthesia research. Anesthesiology 2007; 107: 144-52.

9. Wong SY, Coskunfirat ND, Hee HI, Li JY, Chen C, Tseng CH. Factors influencing time of intubation with a lightwand device in patients without known airway abnormality. J Clin Anesth 2004; 16: 326-31.

10. Barclay K, Eggers K, Asai T. Low-dose rocuronium improves conditions for tracheal intubation after induction of anaesthesia with propofol and alfentanil. Br J Anaesth 1997; 78: 92-4.

11. Siddik-Sayyid SM, Taha SK, Kanazi GE, Chehade JM, Zbeidy RA, Al Alami AA, et al. Excellent intubating conditions with remifentanilpropofol and either low-dose rocuronium or succinylcholine. Can J Anaesth 2009; 56: 483-8.

12. Schlaich N, Mertzlufft F, Soltész S, Fuchs-Buder T. Remifentanil and propofol without muscle relaxants or with different doses of rocuronium for tracheal intubation in outpatient anaesthesia. Acta Anaesthesiol Scand 2000; 44: 720-6.

13. Mencke T, Echternach M, Kleinschmidt S, Lux P, Plinkert PK, Fuchs-Buder T. Intubation-associated vocal cord dysfunction: a randomized, placebo-controlled trial. Eur J Anaesthesiol 2001; 18(Suppl 23): A102.

14. Donati F, Bevan DR. Neuromuscular blocking agent. In: Clinical Anesthesia. 6th ed. Edited by Barash PG, Cullen BF, Stoelting RK, Cahalan MK, Stock MC: Philadelphia, Lippincott William \& Wilkins. 2009, p 503.

15. Shin HS, Lee SI, Lee JH, Lee SC. Effective dose of rocuronium in Koreans. Korean J Anesthesiol 2005; 48: 367-74.

16. Meistelman C, Plaud B, Donati F. Rocuronium (ORG 9426) neuromuscular blockade at the adductor muscles of the larynx and adductor pollicis in humans. Can J Anaesth 1992; 39: 665-9. 